\title{
Life insurance: Ownership and investment considerations
}

\author{
Daniel A Peters MD MBA FRCSC ${ }^{1}$, Douglas A McKay MD MBA FRCSC ${ }^{2}$
}

\begin{abstract}
Ife insurance is an emotional and financial decision that affects Leveryone. There are many different products, with reasons to purchase each type. We consider some of the factors involved in purchasing life insurance.
\end{abstract}

\section{TYPES OF LIFE INSURANCE}

There are two broad classes of insurance policies. These are 'term' and 'universal life' policies (for simplicity, we have included 'whole life' policies under the rubric of universal life).

\section{Term insurance}

Term insurance is what comes to mind when most people contemplate an insurance policy. In this situation, the insured pays a premium to the insurance company on a monthly or yearly basis. These premiums entitle the insured to be paid a benefit in the event of death. The typical policy is applied over a defined period of time. In most instances, the term of the policy is between 10 and 20 years. If that time elapses and the insured is alive there is no residual value remaining in the policy. As a result, $>90 \%$ of term policies never pay any benefits (no wonder insurance companies are so profitable!).

\section{Universal life}

This is a more complicated policy. In this scenario, premiums are also paid; however, a portion of the premium is paid to fund the 'insurance' portion of the policy. The remaining premium serves as an investment. Similar to other managed securities, there is a fund manager who uses this cash to invest in securities. These securities then appreciate and generate income from the policy, which accrues to the policy holder. This accumulated value compounds within the policy.

After a certain period of time, the income derived from these investments is sufficient to underwrite the premiums for the term insurance. As a result, the policy becomes self-funding. No additional premiums are paid in cash by the insured. The policy is effective for the entire life of the individual and is paid on the individual's death. These benefits are paid regardless of the age of the individual. Furthermore, the total benefits represent the amount of insurance that was purchased; in addition, they represent the accrued value of the investment portion of the policy.

Universal life policies have several advantages. The investment component of the policy accumulates tax free. Universal life policies are significantly more likely to pay benefits. In Canada, $>85 \%$ of universal life policies pay benefits. This occurs either at death or when an individual reaches 100 years of age (at which point they are 'dead' to the insurance company). They can also serve as collateral for a loan. However, there are also some disadvantages. These policies are often significantly more expensive compared with term insurance, the investment portion often encompasses a very conservative portfolio of securities with limited asset appreciation, and the policies are very illiquid. Significant penalties result if an individual attempts to withdraw cash from the investment component of the policy.

\section{CONSUMPTION CONSIDERATIONS}

There are many considerations involved in making decisions regarding insurance. Broadly speaking, these considerations fall into four categories: beneficiary considerations, investment considerations, cost and ownership.

\section{Beneficiary considerations}

The first question to ask is whether you need life insurance at all. This really comes down to a question of beneficiary considerations. Is there someone who would be at a significant financial disadvantage as a result of your death?

In most cases, the loss of a family breadwinner will be impactful, but this is not always the case. In some cases, there are multiple breadwinners of equal financial contribution, and the loss of one may not have any financial impact. Some families have other financial resources that functionally render them 'self-insured', and some families leave no dependants. In any of these scenarios, it may be that life insurance is practically not necessary.

In the event that you do not require insurance for a beneficiary, a second question must be considered. Many lenders require debtors to own insurance as a condition of issuing debt. This is a common condition in mortgage requirements, business loans or personal lines of credit. In the event that a debt must be supported by a policy, this ceases to be an issue of life insurance but is functionally a consideration of mortgage insurance.

\section{Investment considerations}

For most of us, one of these beneficiary justifications will be present. Therefore, the question then becomes whether there are reasons to purchase this insurance as part of a comprehensive investment strategy or whether the purpose of the insurance is simply to mitigate financial loss in the event of death.

Term insurance provides no investment advantage in itself. There may be some advantage to an investor in terms of risk stratification. Investors who have an insurance policy as a back stop may be slightly more likely to invest more aggressively. However, the evidence for this justification is scant.

If investment is a primary consideration, a universal life policy is far more interesting. This policy offers the advantages of a managed security. However, insurance regulations allow value accretion and income to accumulate within the policy tax free. This represents a tax shelter for income. At the time of death, the proceeds of an insurance policy are not subject to capital gains or probate in most cases. Consequently, the wealth accumulated within the policy is transferred to the beneficiaries of the policy without incurring taxation. Thus, a universal life policy may represent an effective means of wealth transfer between generations. Whereas other securities incur capital gains taxation at the time of death (as a result of a deemed disposition), the insurance policy is not subject to these taxes.

\footnotetext{
${ }^{1}$ Division of Plastic Surgery, Department of Surgery and Telfer School of Management, University of Ottawa, Ottawa; ${ }^{2}$ Division of Plastic Surgery, Department of Surgery, Queen's University, Kingston, Ontario

Correspondence: Dr Daniel A Peters, University of Ottawa, PO Box 2013, 1053 Carling Avenue, Ottawa, Ontario K1Y 4E9.

Telephone 613-795-5555, fax 613-761-4025, e-mail dannypeters1@gmail.com
} 
The disadvantage of this strategy occurs when one attempts to withdraw income from the policy while he or she is still alive. In that event, penalties and taxation can become quite heavy. Income tax applies, capital gains are incurred and the policy usually has contractual penalties. A more effective strategy for income generation from these policies is to use the policy to serve as collateral for a loan. At the time of death, the loan can be repaid through proceeds from the policy, while the cash generated from the loan can support the lifestyle of the insured during his or her retirement.

\section{Cost}

The cost of these policies is commensurate with their utility. Term insurance is typically quite inexpensive and, although universal life policies are quite expensive by comparison, they are also significantly more variable. In addition to health factors, universal life policies may have much higher premiums depending on the amount of the policy, which is attributed to insurance and the amount that is consumed by investment. Clearly, this heterogeneity is reflected in the value of the policies and the investment objectives of the insured.

\section{Ownership}

The final consideration is who should own the policy. In most cases, individuals purchase insurance policies that are held personally. However, as surgeons, we are in a unique position in which the policies can be purchased by our medical corporations. Clearly, this strategy has tremendous tax advantages. Insurance policies are purchased with after-tax dollars and, by holding the policies in a corporation, the after-tax dollars represent a much higher percentage of pretax income. The key is demonstrating that the corporation has an active interest in the life of the insured, which is relatively easy in the case of a medical corporation.

When the policy is held by the corporation, the death of the insured will result in a payment to the corporation. This is a cash payment, which is not subject to probate or capital gains. The manner in which these payments are then transferred to the beneficiaries of the insured estate can be easily accomplished with estate planning tools (likely a secondary will); however, the details of this are beyond the scope of this article.

In either event, if considering a life insurance policy, each surgeon should consider whether he or she would prefer to hold this policy personally or corporately. This should be discussed with your financial advisor.

\section{CONCLUSIONS}

Life insurance is a complicated discussion that requires individual attention by each consumer. This may be a simple exercise in risk mitigation by a family breadwinner. However, there are sophisticated investment opportunities available. These should be considered in light of overall investment objectives and personal goals. 